\title{
Analysis of Benefits and Barriers as a Critical Success Factor in IT Governance Implementation by Using Interpretive Structural Model
}

\author{
Uky Yudatama, Achmad Nizar Hidayanto and Bobby A.A Nazief \\ Faculty of Computer Science, Universitas Indonesia
}

\author{
Article history: \\ Received: 14-04-2019 \\ Revised: 08-06-2019 \\ Accepted: 24-07-2019 \\ Corresponding Author: \\ Uky Yudatama \\ Faculty of Computer Science, \\ Universitas Indonesia \\ Email: uky.yudatama@ui.ac.id
}

\begin{abstract}
This study aims to identify and analyze the key sub-factors of benefits and barriers as critical success factors for the implementation of IT Governance. The hope of the research is that the results of this identification and analysis can provide a high value of benefits in order to stakeholders in implementing IT Governance. In addition, it is expected to also give a real contribution to the development of theory or concept in the field of IT Governance especially related to critical success factor. The method used in this research is the interpretive structural model, where this method is very suitable to find the key sub-factor with a well-structured hierarchy structure. The first step of this research begins with a literature review, survey and interviews by involving three experts in the field of IT Governance and then the information is processed according to the rules. The final result shows that sub-factors improve customer service and overall responsiveness is a key sub-factor in benefit factors, whereas the lack of financial and human support becomes a key sub-factor in barriers. These results are empirical because depending on the data obtained through expert interviews involved, therefore the quality and capacity of experts greatly affect the results obtained. This study demonstrates how benefits and constraints as a critical success factor in the application of IT Governance are interrelated. The interpretive structural model provides an understanding of how various benefits and barriers interact with each other. This is important because policymakers typically focus on one or two sub-factors only.
\end{abstract}

Keywords: Critical Success Factor, IT Governance, Interpretive Structural Model

\section{Introduction}

IT Governance (Information Technology Governance) is a branch of corporate governance that focuses on information technology systems, performance management and risk. IT Governance is structured IT management and collection of processes that aim to ensure the suitability of IT implementation towards achieving organizational goals, by optimizing the benefits and opportunities offered by IT, controlling the use of IT resources and managing IT-related risks by involving all stakeholders to ensure the success of IT. Therefore IT Governance has a very strategic role in the sustainability of an organization, especially in planning to overcome and reduce the risks that occur (Alreemy et al., 2016).

IT Governance and IT Management are two different things both in terms of the actors or responsible people, their activities and the goals of each (Ali et al., 2015).
From the side of the person in charge, the person in charge of IT Governance is at the level of the board of directors and commissioners. Whereas IT Management is in charge of executive management and line management. IT Governance ensures that all the needs and expectations of the organization's stakeholders have been evaluated when it sets goals that must be achieved by the organization. Then IT Governance provides direction related to priorities and important decisions that need to be taken so that organizational goals can be achieved (Kuusk and Gao, 2015). Then finally, IT Governance monitoring the performance and achievement of the targets and directives that have been set. Whereas IT Management doing the directives given by the board of directors or commissioners to actions that the organization needs to take in order to achieve its intended goals. Based on the directives and guidance from the board of directors or commissioners, the executive management conducts 
from the planning, development of initiatives, service operations, to monitoring its alignment with the directives set by the board of directors or commissioners. All activities of executive management are monitored by the board of directors or commissioners to ensure that executive management performs its duties and responsibilities well in harmony with the direction of the board of directors or commissioners (Alreemy et al., 2016; Ali et al., 2015; Kuusk and Gao, 2015). So that it can be expected that the organizational goals that have been set can be achieved.

IT Governance has a scope among others: IT strategic alignment, value delivery, risk management, IT resource management and performance measurement (Alreemy et al., 2016; Ali et al., 2015). In IT strategic alignment an information technology strategy will be designed that refers to the overall information strategy of an organization and must be in accordance with the business objectives of the organization. Value delivery covers the scope that will target the quality of IT services that are right based on budget and time. Risk management includes good risk management in order to achieve the organization's business goals. Risk management starts with identifying risks and then managing them to be controlled. In addition to the risk of resources, it must also be managed in order to achieve organizational business goals, while one of the resources that must be managed is IT infrastructure (Kuusk and Gao, 2015). Performance measurement includes measurement of performance that is in accordance with the board and senior management.

To implement IT Governance, businesses can take advantage of a range of practices related to decisionmaking structures, processes and relational mechanisms (Henrique et al., 2014; Kuusk and Gao, 2015; Yudatama et al., 2017a). However, the specific contributions of these various practices are still poorly understood (Henrique et al., 2014). While the role of IT Governance is very important (Henrique et al., 2014; Hamid and Sulaiman, 2016; De Haes et al., 2017), many organizations have not been fully aware of the benefits obtained (Yudatama et al., 2017a). Many still use conservative or traditional methods to implement Information Technology Governance (Rychkova and Zdravkovic, 2017). Because of a lack of understanding of the benefits and obstacles to the implementation of IT Governance (Yudatama et al., 2017b), their performance cannot reach the optimum level as expected (Yudatama and Sarno, 2015).

The benefits and obstacles are very basic to know because it can affect the success of IT Governance (Ali et al., 2015; Yudatama et al., 2017a; Al Qassimi and L. Rusu, 2015; Sayogo and Gil-Garcia, 2015). In addition, this also affects the performance of the organization because it deals directly with the user especially in response to accepting or rejecting something given to him well or not (Yudatama et al., $2017 b-c)$. Therefore, the benefits and barriers are very important that can determine success which is often referred to as a determinant of success (Yudatama et al., 2018).

Although there are several studies that look at the problems of benefits and obstacles in adopting the implementation of IT Governance in developing countries, in general only a few have succeeded (Yudatama et al., 2107c; Shelly et al., 2015; Yadav and Barve, 2015). These challenges include a lack of understanding of benefits and barriers (Jayant and Azhar, 2014; Zou et al., 2014). The main problem often faced by top management is the lack of understanding of the main factors and sub-factors that influence the successful implementation of IT Governance (De Haes et al., 2017; Yudatama and Sarno, 2015; Shelly et al., 2015; Tokta et al., 2014; Badewi, 2016; Sabry, 2014; Denolf et al., 2015), making it less appropriate to make decisions or policies (Tokta et al., 2014; Hatsu and Ngassam, 2015). Therefore, how to find out the main factors and sub-factors becomes something very important and significant to be known and understood by top management (Hamid and Sulaiman, 2016; De Haes et al., 2017; Badewi, 2016; Sabry, 2014; Denolf et al., 2015).

This study aims to identify and analyze the key subfactors of benefits and barriers that become Critical Success Factor in the application of IT Governance with using Interpretive Structural Model (Rychkova and Zdravkovic, 2017; Jayant and Azhar, 2014). Where Interpretive Structural Model is a modeling technique capable of synchronizing the opinions of experts to give a concrete description of the sub-factors hierarchy structure and can find the key sub-factor of each factor (Rychkova and Zdravkovic, 2017; Jayant and Azhar, 2014; Tokta et al., 2014), as a useful knowledge base for strategy planning (Al Qassimi and Rusu, 2015), so that it will provide high benefit value (Yudatama et al., 2017a). Interpretive Structural Model is a comprehensive and systematic model of various elements that are directly or indirectly related to each predetermined problem (Rychkova and Zdravkovic, 2017), where decisions between these interdependent variables are based on evaluations from experts (interpretative) (Jayant and Azhar, 2014). In addition, another goal of using Interpretive Structural Model is to analyze complex problems using systematic and logical thinking supported by expert judgment (Tokta et al., 2014). Interpretive Structural Model has been successfully practiced in the field of green supply chain management (Jayant and Azhar, 2014) and for industry 4.0 adoption challenges (Karadayi, 2019).

In this study, it has been discussed about important factors and sub-factors using the Interpretive Structural Model beginning with the introduction containing the background of the research carried out, then proceeding with the literature which is the support in this study, 
followed by research methods as work directions and stages. The next discussing the research methodology, continued by discussing the results and discussion. The last section closes with conclusions and research into the future by providing future research suggestions and input.

Expectations from the results of this study provide discourse about important sub-factors, both in terms of benefits and obstacles in the implementation of IT Governance. In addition, it provides a clear picture of how relationships are structured and interrelated so that this can be a valuable inspiration for all parties involved in implementing IT Governance to make it better. Or the results of these findings can be used as a first step to develop a model in the future.

\section{Literature Study}

This research has observed the critical success subfactors towards the implementation of IT Governance. There are two important factors that are observed in this literature study, that is, everything related to the benefits and barriers in the implementation of IT Governance. Some credible databases such as Science Direct, IEEE and Scopus have a number of highly qualified articles we collect for making into reference. By considering the literature relating to the theme, especially about the basic concepts of benefits and barriers as a critical success factor, other than that with slightly considering the year (5 years back/2014) and using the PRISMA metaanalysis model.

PRISMA is a model used to search for basic literature relating to the topic of research that will be done. With this model, we will find it easier to get literature because it is guided through several structured and systematic stages so that the results can be in accordance with what we expect. We chose to use PRISMA, because this model is easy to understand and follow which consists of several structured and systematic stages, making it easy to do, if these steps are followed correctly and well, then we will get a quality reference (İnci and Griffiths, 2019).

We have identified 85 articles according to the topic of this study, 6 articles were found to be duplicates, so we removed them from the list. Our next step is screening, 79 articles are filtered by referring to the title and abstract, found 70 suitable articles. From these 70 articles, we double check to see the feasibility of each paper. The final results, 37 articles were used as the main study literature. Fig. 1 shows a flow diagram of the literature search process.

\section{Benefits}

To support the routine of activities in an organization, IT Governance has a very important role. Routine work will be easier and faster to do because it is assisted by using information technology and its application, this is the right solution because it can improve quality better. Some literature that discusses benefits has been found and shown in Table 1.

\section{Barriers}

The implementation of IT Governance cannot all work well as expected. This is because there are several things that can affect the implementation. Therefore, it is necessary to know and identify what things are hindering it. Table 2 shows the things that can hinder the success of the implementation of IT Governance that we have obtained through a literature review.
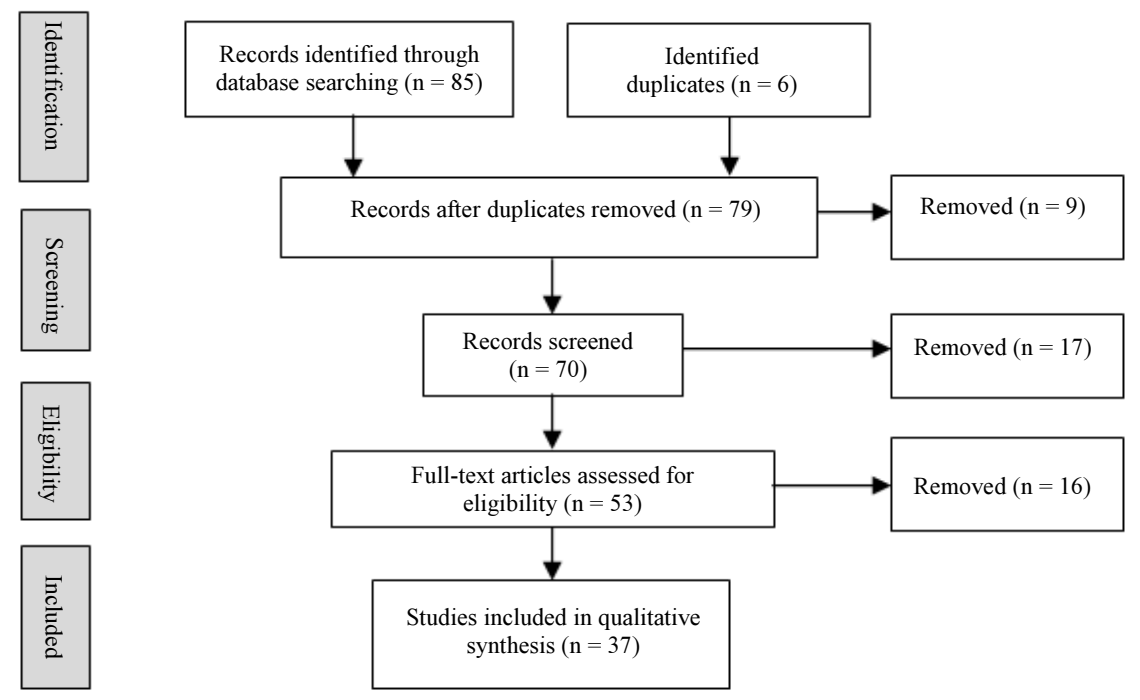

Fig. 1: Flowchart of the article search process 
Table 1: Result of study on benefits reference

\begin{tabular}{|c|c|}
\hline Benefits & Reference \\
\hline $\begin{array}{l}\text { Aligning business } \\
\text { priorities and IT } \\
\text { investments (M1) }\end{array}$ & $\begin{array}{l}\text { Ali et al. (2015; Henrique etal.,2014; Hamid and Sulaiman, 2016; De Haes et al., 2017; Al Qassimi and Rusu, } 2015 \text {; } \\
\text { Yadav and Barve, 2015; Bianchi and Sousa, 2016; Altemimi and Zakaria, 2015) }\end{array}$ \\
\hline $\begin{array}{l}\text { Manage and } \\
\text { monitor funds more } \\
\text { consistently (M2) }\end{array}$ & $\begin{array}{l}\text { Ali et al. (2015; Yudatama et al., 2017a; Hamid and Sulaiman, 2016; Yudatama et al., 2018; Shelly et al., 2015; } \\
\text { Yudatama and Sarno, 2016; Ali et al., 2015; Smits and Hillegersberg, 2018; Majid et al., 2015; Pau et al., 2016; } \\
\text { Bobbert and Mulder, 2015; El-mekawy et al., 2015) }\end{array}$ \\
\hline $\begin{array}{l}\text { Managing resource } \\
\text { and assets in a } \\
\text { responsible manner (M3) }\end{array}$ & $\begin{array}{l}\text { Ali et al. (2015; Henrique etal., 2014; Yudatama et al., 2017c; De Haes et al., 2017; Al Qassimi and Rusu, 2015; Teh } \\
\text { and Corbitt, 2015; Yudatama et al., 2107c; Shelly et al., 2015; Yadav and Barve, 2015; Jayant and Azhar, 2014; Zou et al., } \\
\text { 2014; Badewi, 2016; Sabry, 2014; Denolf et al., 2015; Hatsu and Ngassam, 2015; Bianchi and Sousa, 2016; Altemimi } \\
\text { and Zakaria, 2015; Smits and Hillegersberg, 2018; El-mekawy et al., 2015; Yudatama et al., 2017d; Safdar et al., 2015) }\end{array}$ \\
\hline $\begin{array}{l}\text { Ensuring that IT delivers } \\
\text { on plans, budgets and } \\
\text { commitments (M4) }\end{array}$ & $\begin{array}{l}\text { Kuusk and Gao (2015; Hamid and Sulaiman, 2016; De Haes et al. (2017; Yudatama and Sarno, 2015; Teh and Corbitt, } \\
\text { 2015; Yudatama et al., 2018; Yudatama et al., 2107c; Shelly et al., 2015; Jayant and Azhar, 2014; Zou et al., 2014; } \\
\text { Badewi, 2016; Sabry, 2014; Denolf et al., 2015; Hatsu and Ngassam, 2015; Majid et al., 2015; Bobbert and Mulder, } \\
\text { 2015; El-mekawy et al., 2015; Safdar et al., 2015) }\end{array}$ \\
\hline $\begin{array}{l}\text { Establish and clarify } \\
\text { accountability and } \\
\text { decision rights (M5) }\end{array}$ & $\begin{array}{l}\text { Ali et al. (2015; Kuusk and Gao, 2015; Paper, 2015; Yudatama et al., 2017a; Hamid and Sulaiman, 2016; Al Qassimi } \\
\text { and Rusu, 2015; Sayogo and Gil-Garcia, 2015; De Haes et al., 2017; Bianchi and Sousa, 2016; Altemimi and } \\
\text { Zakaria, 2015; Smits and Hillegersberg, 2018) }\end{array}$ \\
\hline $\begin{array}{l}\text { Managing risk, change } \\
\text { contingency } \\
\text { proactively (M6) }\end{array}$ & $\begin{array}{l}\text { Kuusk and Gao (2015; Henrique et al., 2014; Yudatama et al., 2017a; Hamid and Sulaiman, 2016; Rychkova and } \\
\text { Zdravkovic, 2017; Sayogo and Gil-Garcia, 2015; Yudatama et al., 2018; Jayant and Azhar, 2014; Sabry, 2014; } \\
\text { Bianchi and Sousa, 2016; Smits and Hillegersberg, 2018; Bobbert and Mulder, 2015) }\end{array}$ \\
\hline Improve customer service & Badewi (2016; Altemimi and Zakaria, 2015; Yudatama et al., 2017d) \\
\hline
\end{tabular}

Table 2: Result of study on barriers reference

\begin{tabular}{ll}
\hline Barriers & Reference \\
\hline $\begin{array}{l}\text { Lack of understanding of } \\
\text { the regulation (P1) }\end{array}$ & Paper (2015; Teh and Corbitt, 2015; Shelly et al., 2015; Hatsu and Ngassam, 2015) \\
Inadequate regulation (P2) & $\begin{array}{l}\text { Hamid and Sulaiman (2016; De Haes } \text { et al., 2017; Zou et al., 2014; Tokta } \text { et al., 2014; Sabry, 2014; } \\
\text { Hatsu and Ngassam, 2015; Yudatama et al., 2017d; Safdar et al., 2015) }\end{array}$ \\
$\begin{array}{l}\text { The lack of persuasive } \\
\text { communication (P3) }\end{array}$ & $\begin{array}{l}\text { Ali } \text { et al. (2015; Yudatama } \text { et al., 2017a-b; Yudatama and Sarno, 2015; Teh and Corbitt, 2015; Shelly } \\
\text { et al., 2015 Zou } \text { et al., 2014; Yudatama and Sarno, 2016; Denolf et al., 2015; Bianchi and Sousa, 2016; }\end{array}$ \\
& Altemimi and Zakaria, 2015; El-mekawy et al., 2015) \\
Top management less & Zou et al. (2014; Badewi, 2016; Sabry, 2014; Hatsu and Ngassam, 2015; Bobbert and Mulder, 2015)
\end{tabular}

Top management less committed (P4)

Lack of financial support Ali et al. (2015; Henrique etal.,2014; Yudatama et al., 2017a; De Haes et al., 2017; Yudatama and Sarno, and human (P5) 2015; Sayogo and Gil-Garcia, 2015; Zou et al., 2014; Yudatama and Sarno, 2016; Denolf et al., 2015; Altemimi and Zakaria, 2015; Majid et al., 2015; El-mekawy et al., 2015)

There is no perspective of Kuusk and Gao(2015; Yudatama et al., 2017a; Hamid and Sulaiman, 2016; De Haes et al., 2017)

business and IT

integration (P6)

IT staff lack business- $\quad$ Kuusk and Gao (2015; Henrique etal., 2014; Al Qassimi and Rusu, 2015; Teh and Corbitt, 2015; Yudatama oriented (P7) and Sarno, 2016; Badewi, 2016; Denolf et al., 2015; Pau et al., 2016)

\section{Research Methodology}

The implementation of this research is divided into six stages, namely (1) Determination of research topic, (2) Literature study and review it to become reference material related to critical success factor, (3) Identify critical success factor on IT Governance implementation based on benefit and barriers, (4) Data collection is done by using descriptive method which is explored from survey and interview through questionnaire filling by competent experts, (5) Data processing with Interpretive Structural Modeling method. (6) Conclusions the complete stages of the study are shown in Fig. 2.

The data collected consisted of secondary data and primary data, secondary data obtained through literature review related to the implementation of IT Governance especially related to critical success factors. While for primary data is data directly obtained and done directly by the researcher, in this study primary data among them is knowledge data owned by experts in the field of practitioners and academics and government in the field of IT Governance. To obtain this data will be arranged tool in the form of questionnaires that have been designed in accordance with the purpose.

We have interviewed 3 experts, in this case, people who have very special knowledge, experience and abilities in the field of IT Governance. This person was chosen based on recognition by many parties, has a good reputation and has produced several works of innovation in the field of IT Governance. Why do we only involve 3 experts, this is because we are more focused and serious about getting data. 


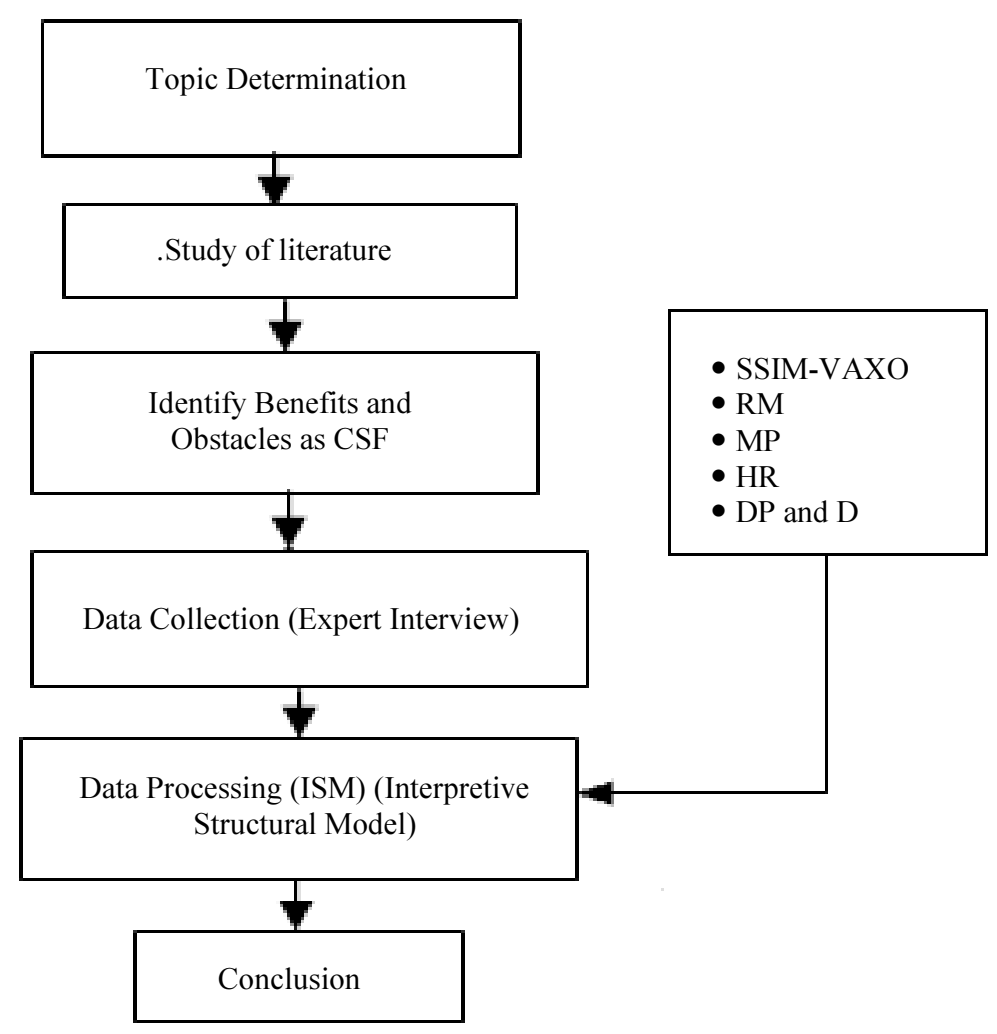

Fig. 2: Stages of research methodology

The sample size that we use involves 3 experts, this in accordance with the Karadayi (2019) statement, that in order to obtain accurate information, at least involve 3 experts who are competent in their fields. An expert is someone who has the knowledge, experience, abilities and skills in his field that has been proven by the results of his work and credibility recognized by others. Experts have the knowledge, experience and abilities so that they can provide input relating to information that is important in this study. The profiles of the experts involved in this study all have experience working over 25 years with an educational background in S3 Computer Science in IT Governance. We have interviewed by meeting and communicating experts directly at the object of the research, by asking some questions that had been prepared. The results of our interviews noted and if we find an ambiguous or contradictory answer between experts, we ask for clarification, so we get the same answer.

The data have been obtained from the knowledge of 3 experts drawn from practitioners, academicians and government through questionnaires which are then processed by data processing using Interpretive Structural Model method determine the key sub-factors for the formulation in the development strategy of benefit factor and barriers as critical success factor In the application of IT Governance. The steps in the Interpretive Structural Model method are divided into 5 stages: (a) Preparation of Structural Self-Interaction Matrix-VAXO (SSIM-VAXO), (b) SSIM-VAXO Transformation into Reachability Matrix (RM) binary numbers, (c) Matrix Position (MP), (d) Preparation of Hierarchy based on sub-element Rankings (HR) and (e) Sub-element classification/cluster diagram based on Driver Power (DP) and Dependence (D).

\section{Results}

This section discusses the results of research related to what has been obtained from this study. There are two parts that are the focus in this section, namely the benefit factor and the barrier factor.

\section{Benefit Factor Analysis}

The data obtained from the experts is then processed into SSIM-VAVO as shown in Table 3.

Initial Data Reachability Matrix from Table 3 (SSIMVAXO), then converted to binary Reachability Matrix (RM), as shown in Table 4. A transitive test for the consistency of the Reachability Matrix (RM) is required to obtain the Final Reachability Matrix as shown in Table 5. 
From Table 5 above, it can be seen that the sub-factor M7 with has the smallest value Driving Power value (DP = 1 but Dependence $=7$ ) and sub-factor M1 with has the biggest value Driving Power ( $\mathrm{DP}=7$ but Dependence $=1$ ).

Table 6 shows that the first iteration process begins with respect to the smallest Driving Power value (DP $=1$ ) resulting in $\mathrm{M} 7$ sub-factors as level 1 .

Table 7 shows the second iteration process taking into account the rather large Driving Power value (DP =6), resulting in the M2, M3, M4, M5 and M6 subfactor as level 2 .
Table 8 showing the third iteration process with into account the largest Driving Power value (DP $=7$ ), resulting in M1 sub-factor as level 3.

Table 3: Self structural interpreting model (SSIM-VAXO)

\begin{tabular}{lllllll}
\hline Variable & M7 & M6 & M5 & M4 & M3 & M2 \\
\hline M1 & 0 & V & V & V & V & V \\
M2 & 0 & V & A & A & X & \\
M3 & 0 & X & X & X & & \\
M4 & V & V & X & & & \\
M5 & V & X & & & & \\
M6 & V & & & & & \\
\hline
\end{tabular}

Table 4: Reachability matrix of benefits factor

\begin{tabular}{llllllll}
\hline Variable & M1 & M2 & M3 & M4 & M5 & M6 & M7 \\
\hline M1 & 0 & 1 & 1 & 1 & 1 & 1 & 1 \\
M2 & 0 & 1 & 0 & 0 & 1 & 1 & 0 \\
M3 & 0 & 1 & 1 & 1 & 1 & 1 & 0 \\
M4 & 1 & 1 & 1 & 1 & 1 & 1 & 0 \\
M5 & 1 & 1 & 1 & 1 & 1 & 0 & 0 \\
M6 & 1 & 1 & 0 & 0 & 0 & 0 & 0 \\
M7 & 1 & 0 & & &
\end{tabular}

Table 5: Final reachability matrix of benefits factor

\begin{tabular}{llcccccccc}
\hline Variable & M1 & M2 & M3 & M4 & M5 & M6 & M7 & Driving Power & Rank \\
\hline M1 & 1 & 1 & 1 & 1 & 1 & 1 & $* 1$ & 7 & III \\
M2 & 0 & 1 & 1 & $* 1$ & $* 1$ & 1 & $* 1$ & 6 & II \\
M3 & 0 & 1 & 1 & 1 & 1 & 1 & $* 1$ & 6 & II \\
M4 & 0 & 1 & 1 & 1 & 1 & 1 & 1 & 6 & II \\
M5 & 0 & 1 & 1 & 1 & 1 & 1 & 1 & 6 & II \\
M6 & 0 & $* 1$ & 1 & $* 1$ & 1 & 1 & 1 & 6 & II \\
M7 & 0 & 0 & 0 & 0 & 0 & 0 & 1 & 1 & I \\
Dependence & 1 & 6 & 6 & 6 & 6 & 6 & 7 & & \\
\hline
\end{tabular}

Table 6: Iteration of benefits factor level I (M7)

\begin{tabular}{llll}
\hline Variable & Reachability set & Antecedent set & Intersection set \\
\hline M1 & $1,2,3,4,5,6,7$ & 1 & 1 \\
M2 & $2,3,4,5,6,7$ & $1,2,3,4,5,6$ & $2,3,4,5,6$ \\
M3 & $2,3,4,5,6,7$ & $1,2,3,4,5,6$ & $2,3,4,5,6$ \\
M4 & $2,3,4,5,6,7$ & $1,2,3,4,5,6$ & $2,3,4,5,6$ \\
M5 & $2,3,4,5,6,7$ & $1,2,3,4,5,6$ & $2,3,4,5,6$ \\
M6 & $2,3,4,5,6,7$ & $1,2,3,4,5,6$ & $2,3,4,5,6$ \\
M7 & 7 & $1,2,3,4,5,6$ & 1 \\
\hline
\end{tabular}

Table 7: Iteration of benefits factor level II (M2, M3, M 4, M5, M6)

\begin{tabular}{lllll}
\hline Variable & Reachability set & Antecedent set & Intersection set & Level \\
\hline M1 & $1,2,3,4,5,6$ & 1 & 1 & \\
M2 & $2,3,4,5,6$ & $1,2,3,4,5,6$ & $2,3,4,5,6$ & II \\
M3 & $2,3,4,5,6$ & $1,2,3,4,5,6$ & $2,3,4,5,6$ & II \\
M4 & $2,3,4,5,6$ & $1,2,3,4,5,6$ & $2,3,4,5,6$ & II \\
M5 & $2,3,4,5,6$ & $1,2,3,4,5,6$ & $2,3,4,5,6$ & II \\
M6 & $2,3,4,5,6$ & $1,2,3,4,5,6$ & $2,3,4,5,6$ & II \\
\hline
\end{tabular}

Table 8: Iteration of benefits factor level III (M1)

\begin{tabular}{lllll}
\hline Variable & Reachability set & Antecedent set & Intersection set & Level \\
\hline M1 & 1 & 1 & 1 & III \\
\hline
\end{tabular}




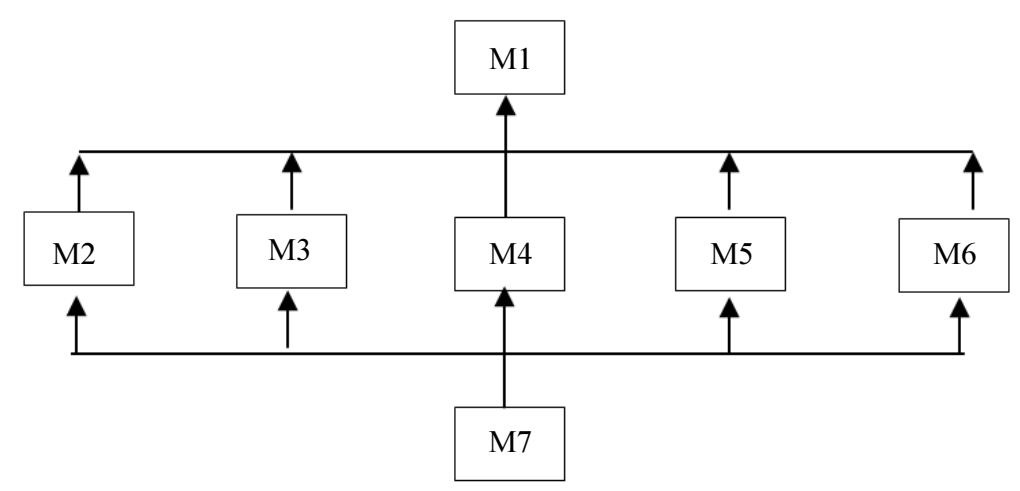

Fig. 3: Structural model hierarchy of Benefits Factor

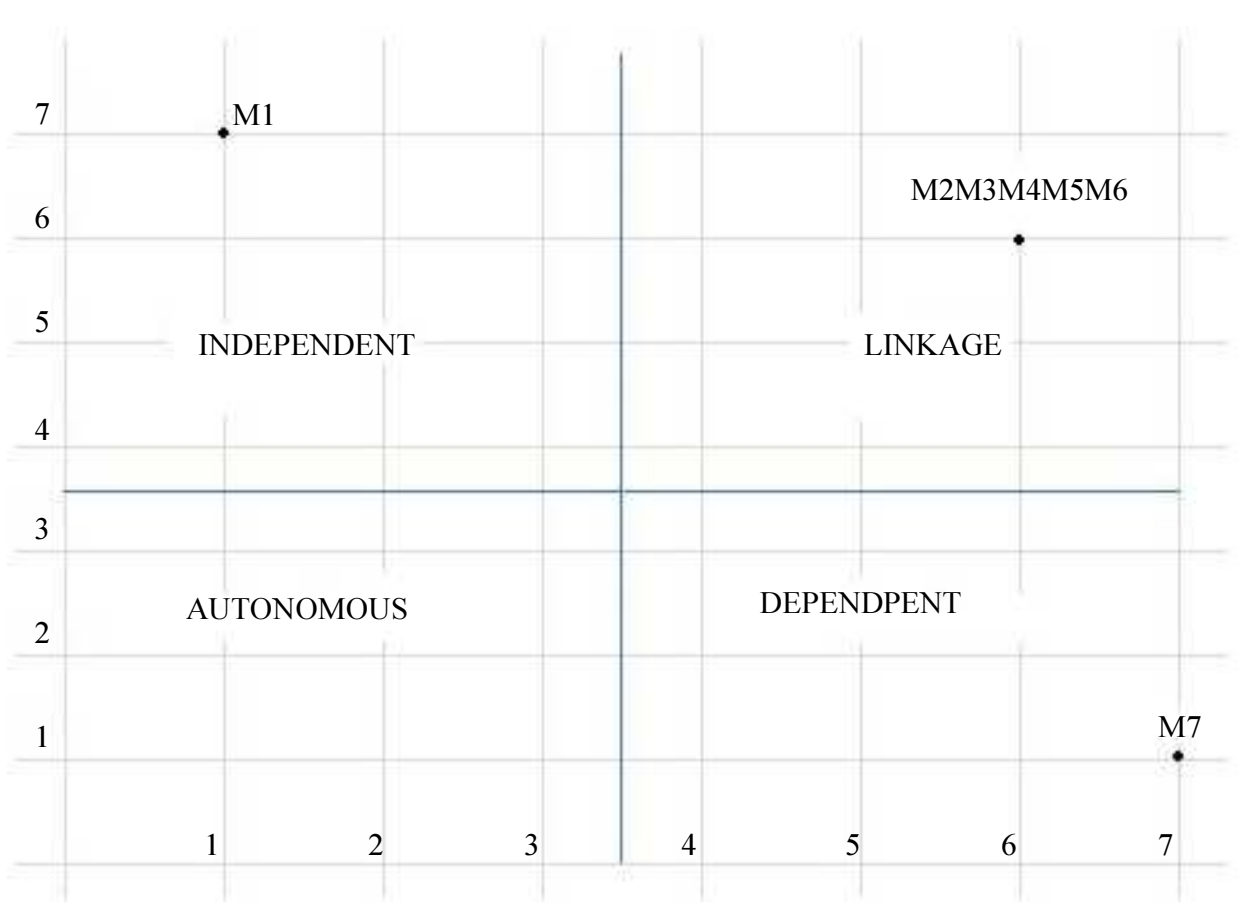

Fig. 4: Cluster diagram of Benefits Factor

Figure 3 shows the Structural hierarchy of Benefits Factor models while in Fig. 4 shows the Cluster diagram of Benefits Factor.

\section{Barriers Factor Analysis}

The data obtained from the experts is then processed into SSIM-VAVO as shown in Table 9.

Initial Data Reachability Matrix from Table 9 (SSIMVAXO), then converted to binary Reachability Matrix (RM), as shown in Table 10. A transitive test for the consistency of the Reachability Matrix (RM) is required to obtain the Final Reachability Matrix as shown in Table 10.

From Table 11 above, it can be seen that the subfactor P5 with has the smallest value Driving Power value (DP $=1$ but Dependence $=7$ ) and sub-factors P1,
P2, P3 and P4 with have the biggest value Driving Power (DP $=7$ but Dependence $=4)$.

Table 12 shows that the first iteration process begins with respect to the smallest driver power value (Driving Power $=1$ ) and has dependence $=7$, resulting in P5 subfactors as level 1 .

Table 13 shows the second iteration process taking into account the rather large Driving Power value (DP = 2), resulting in the P6 sub-factor as level 2.

Table 14 showing the fourth iteration process with into account the large Driving Power value ( $\mathrm{DP}=3$ ), resulting in $\mathrm{P} 7$ sub-factor as level 3.

Table 15 showing the fourth iteration process with into account the largest Driving Power value (DP $=7$ ), resulting in $\mathrm{P} 1, \mathrm{P} 2, \mathrm{P} 3$ and $\mathrm{P} 4$ sub-factor as level 4. 
Figure 5 shows the Structural hierarchy of Barriers Factor models while in Fig. 6 shows the Cluster diagram of Barriers Factor.

Table 9: Self structural interpreting model VAXO

\begin{tabular}{lllllll}
\hline Variable & P7 & P6 & P5 & P4 & P3 & P2 \\
\hline P1 & V & V & V & A & X & A \\
P2 & V & V & V & V & V & \\
P3 & V & V & V & X & & \\
P4 & V & V & V & & & \\
P5 & A & A & & & & \\
P6 & X & & & & & \\
\hline
\end{tabular}

Table 10: Reachability matrix of barriers factor

\begin{tabular}{llllllll}
\hline Variable & P1 & P2 & P3 & P4 & P5 & P6 & P7 \\
\hline P1 & 1 & 1 & 1 & 0 & 1 & 0 & 1 \\
P2 & 1 & 1 & 1 & 1 & 1 & 1 & 1 \\
P3 & 1 & 0 & 1 & 1 & 1 & 0 & 1 \\
P4 & 1 & 0 & 1 & 1 & 1 & 0 & 0 \\
P5 & 0 & 0 & 0 & 0 & 1 & 0 & 0 \\
P6 & 0 & 0 & 0 & 0 & 1 & 1 & 0 \\
P7 & 0 & 0 & 0 & 0 & 1 & 1 & 1 \\
\hline
\end{tabular}

Table 11: Final reachability matrix of barriers factor

\begin{tabular}{llrlllrrrr}
\hline Variable & P1 & P2 & P3 & P4 & P5 & P6 & P7 & Driving power & Rank \\
\hline P1 & 1 & 1 & 1 & $* 1$ & 1 & $* 1$ & 1 & 7 & IV \\
P2 & 1 & 1 & 1 & 1 & 1 & 1 & 1 & 7 & IV \\
P3 & 1 & $* 1$ & 1 & 1 & 1 & $* 1$ & 1 & 7 & IV \\
P4 & 1 & $* 1$ & 1 & 1 & 1 & $* 1$ & $* 1$ & 7 & IV \\
P5 & 0 & 0 & 0 & 0 & 1 & 0 & 0 & 1 & I \\
P6 & 0 & 0 & 0 & 0 & 1 & 1 & 0 & 2 & II \\
P7 & 0 & 0 & 0 & 0 & 1 & 1 & 1 & 3 & III \\
Dependence & 4 & 4 & 4 & 4 & 7 & 6 & 5 & & \\
\hline
\end{tabular}

Table 12: Iteration of barriers factor (P5)

\begin{tabular}{|c|c|c|c|c|}
\hline Variable & Reachability set & Antecedent set & Intersection set & Level \\
\hline$\overline{P 1}$ & $1,2,3,4,5,6,7$ & $1,2,3,4$ & $1,2,3,4$ & \\
\hline $\mathrm{P} 2$ & $1,2,3,4,5,6,7$ & $1,2,3,4$ & $1,2,3,4$ & \\
\hline P3 & $1,2,3,4,5,6,7$ & $1,2,3,4$ & $1,2,3,4$ & \\
\hline P4 & $1,2,3,4,5,6,7$ & $1,2,3,4$ & $1,2,3,4$ & \\
\hline P5 & 5 & $1,2,3,4,5,6,7$ & 5 & I \\
\hline P6 & 5,6 & $1,2,3,4,6,7$ & 6 & \\
\hline P7 & $5,6,7$ & $1,2,3,4,7$ & 7 & \\
\hline
\end{tabular}

Table 13: Iteration of barriers factor (P6)

\begin{tabular}{|c|c|c|c|c|}
\hline Variable & Reachability set & Antecedent set & Intersection set & Level \\
\hline $\mathrm{P} 1$ & $1,2,3,4,6,7$ & $1,2,3,4$ & $1,2,3,4$ & \\
\hline $\mathrm{P} 2$ & $1,2,3,4,6,7$ & $1,2,3,4$ & $1,2,3,4$ & \\
\hline P3 & $1,2,3,4,6,7$ & $1,2,3,4$ & $1,2,3,4$ & \\
\hline P4 & $1,2,3,4,6,7$ & $1,2,3,4$ & $1,2,3,4$ & \\
\hline P6 & 6 & $1,2,3,4,6,7$ & 6 & II \\
\hline P7 & 6,7 & $1,2,3,4,7$ & 7 & \\
\hline
\end{tabular}

Table 14: Iteration of barriers factor (P7)

\begin{tabular}{lllll}
\hline Variable & Reachability set & Antecedent set & Intersection set & Level \\
\hline P1 & $1,2,3,4,7$ & $1,2,3,4$ & $1,2,3,4$ \\
P2 & $1,2,3,4,7$ & $1,2,3,4$ & $1,2,3,4$ \\
P3 & $1,2,3,4,7$ & $1,2,3,4$ & $1,2,3,4$ \\
P4 & $1,2,3,4,7$ & $1,2,3,4$ & $1,2,3,4$ \\
P7 & 7 & $1,2,3,4,7$ & 7 & III \\
\hline
\end{tabular}

Table 15: Iteration of barriers factor (P1, P2, P3, P4)

\begin{tabular}{lllll}
\hline Variable & Reachability set & Antecedent set & Intersection set & Level \\
\hline P1 & $1,2,3,4$ & $1,2,3,4$ & $1,2,3,4$ & IV \\
P2 & $1,2,3,4$ & $1,2,3,4$ & $1,2,3,4$ & IV \\
P3 & $1,2,3,4$ & $1,2,3,4$ & $1,2,3,4$ & IV \\
P4 & $1,2,3,4$ & $1,2,3,4$ & $1,2,3,4$ & IV \\
\hline
\end{tabular}




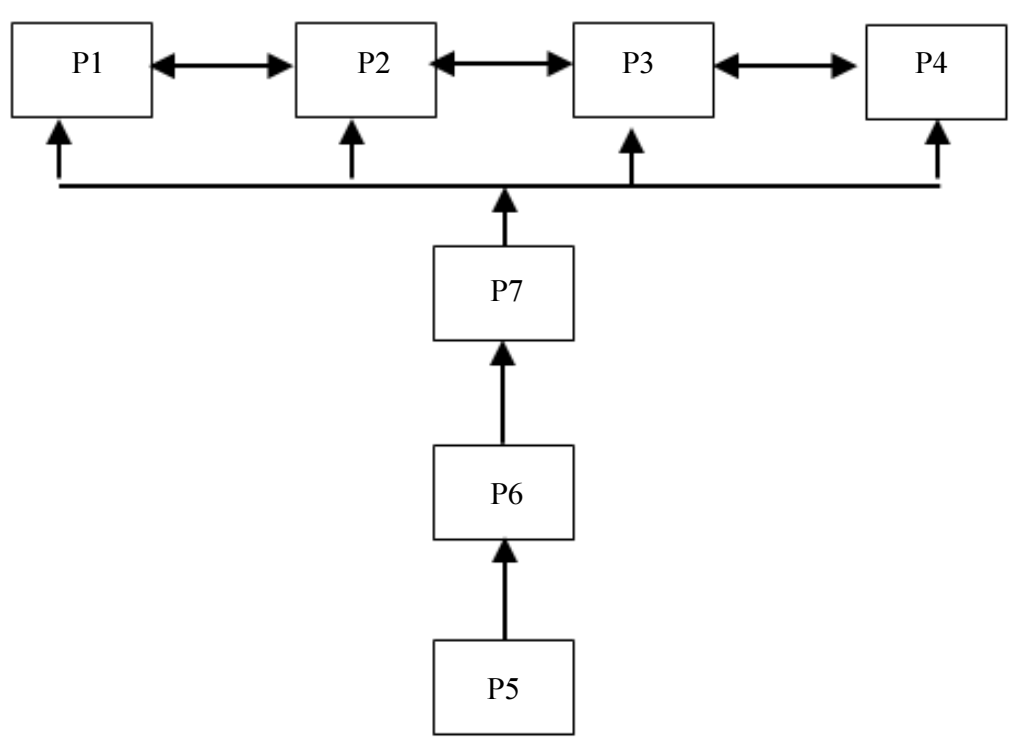

Fig. 5: Structural model hierarchy of the barriers factor

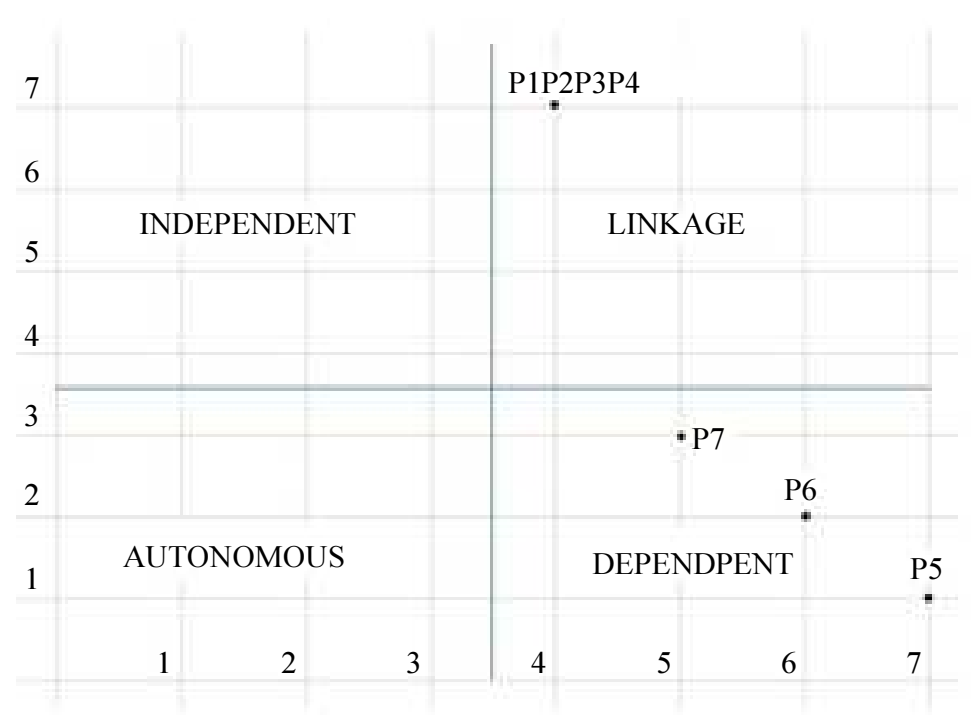

Fig. 6: Cluster diagram of barriers factor

\section{Discussion}

From Fig. 3 it can be seen that M7 located at the bottom, this means that M7 can be said to be the foundation of the other sub-factors and is also a key subfactors. As the key sub-factors, of course, this needs serious attention because it has a great influence and as a driving force of other sub-factors. Unlike the M1 that occupies the top position supported by five sub-factors namely; M2, M3, M4, M5 and M6. Although M1 is subfactors that are considered less important than others, M1 should not be ignored. M1 will be achieved well if sub-factors below it can also work and run well too.
Figure 4 it is clear that M1 is Sub-factors located in independent quadrants meaning that these sub-factors are sub-factors independent of other sub-factors. Therefore the success of this sub-factors the trigger for the success of other sub-factors such as the M7 sub-factor included in the dependent quadrant.

From Fig. 5 it can be analyzed that P5 is a key sub factors compared to other sub factors. It is the foundation as a buffer above it. Therefore, it should get very serious attention from all parties involved so that barriers in the implementation of IT Governance can be minimized as possible. The interesting thing about these findings is that at level IV there are 4 sub-factors that occupy it, namely P1, P2, P3 and P4. These four sub factors seem 
to be sub-factors that often become a barrier to almost all organizations, So it would be better if all parties involved together to solve this problem, especially at the top level of management, should be focused and committed to addressing this issue.

Figure 6 shows that sub-factors such as P5, P6 and P7 are included in the dependent quadrant, which means that these sub-factors are dependent on the other subfactors. This sub factors has something to do with the P1, P2, P3 and P4 sub-factors that fall within the linkage quadrant, which means that these sub-factors have instability properties and can affect other sub-factors. Therefore it is necessary to be careful that other subfactors are not affected.

\section{Conclusion}

The result of identification and analysis of using the interpretive structural model method found that sub factors improving customer service and responsiveness as a whole (M7) Become a key sub-factor of the benefits factor. Sub factors Aligning business priorities and IT Investments (M1) is the most independent sub-element, meaning that this sub-element is a sub-element that does not depend on other sub-elements. Therefore the success of this sub factors may be the trigger for the success of the sub factors of the other. As for barriers, sub-factors of lack of financial and human support (P5) are key Subfactors, while P5, P6 and P7 are included in the dependent quadrant, meaning that this sub factors are dependent on other sub factors. Therefore there is a need for caution in sub-factors such as P1, P2, P3 and P4 because this sub-factors belongs to the linkage quadrant, it means that in this sub-factor has the nature of instability and can affect the sub-factors another.

\section{Research Future}

In this study, 7 benefits and 7 barriers have been found, maybe in the future more of these factors will emerge, besides this research is more qualitative, especially in obtaining data obtained through interviews and opinions of experts. Therefore, in the future, it is necessary to develop and conduct quantitative research, for example by using the Structural Equation Model, where this model involves more people so that the results may be different from the research that has been done. Statistical analysis and graphs on future research can be used to measure sub-factors at the benefits and barriers.

\section{Implications}

This model shows how benefits and constraints as critical success factors in the implementation of IT Governance are interrelated. Interpretive Structural Model provides an understanding of how the various benefits and barriers interact with each other. This is important because in general policymakers typically focus on only a few sub-factors (Hamid and Sulaiman, 2016; Yudatama et al., 2018; Altemimi and Zakaria, 2015). The Interpretive Structural Model used in this study will enable to provide a clear picture to policymakers to better understand the benefits and barriers in implementing IT Governance (Rychkova and Zdravkovic, 2017; Jayant and Azhar, 2014; Tokta et al., 2014). Decision makers should be aware of the relative importance of benefits and constraints in implementing IT Governance, even if the model is based on the opinions of experts (Hamid and Sulaiman, 2016; Rychkova and Zdravkovic, 2017; Jayant and Azhar, 2014). The results of this study will certainly help a lot in implementing better, more effective and efficient future IT Governance. It can also assist strategic and tactical decisions for policymakers within an organization. Benefits are encouraged to be optimized as long as the barriers are kept to a minimum so there will be great results (Yudatama et al., 2017a).

\section{Acknowledgments}

The author would like to thank the friends of Doctoral Program of the Computer Science University of Indonesia force a Thesis Grant for the doctoral student of the University of Indonesia with number: 1562/UN2.R3.1/PPM.00.01/2018, besides this research, has no conflict of interest with anyone and any group.

\section{Ethics}

This article is the original contribution of the authors and is not published elsewhere. There is no ethical issue involved in this article.

\section{Author's Contributions}

Uky Yudatama: Selected the topic and analyzed the literature along with proposing and implementing the methods.

Achmad Nizar Hidayanto: Supervising the research by reviewing the manuscript iteratively and giving suggestions and recommendations.

Bobby A.A Nazief: Coordinated the data-analysis and contributed to the review of the manuscript.

\section{References}

Al Qassimi, N. and L. Rusu, 2015. IT Governance in a public organization in a developing country: A case study of a governmental organization. Procedia Comput. Sci., 64: 450-456.

Ali, S., P. Green and A. Robb, 2015. Information technology investment governance: What is it and does it matter? Int. J. Account. Inform. Syst., 18: 125. DOI: $10.1016 /$ j.accinf.2015.04.002 
Alreemy, Z., V. Chang, R. Walters and G. Wills, 2016. Critical Success Factors (CSFs) for Information Technology Governance (ITG). Int. J. Inform. Manage., 36: 907-916.

Altemimi, A.H. and M.S. Zakaria, 2015. Developing factors for effective IT Governance mechanism. Proceedings of the 9th Malaysian Software Engineering Conference, Dec. 16-17, IEEE Xplore Press, Kuala Lumpur, Malaysia, pp: 25-15. DOI: 10.1109/MySEC.2015.7475228

Badewi, A., 2016. The impact of Project Management (PM) and Benefits Management (BM) practices on project success: Towards developing a project benefits governance framework. Int. J. Project Management, 34: 761-778.

DOI: 10.1016/j.ijproman.2015.05.005

Bianchi, I.S. and R.D. Sousa, 2016. IT Governance mechanisms in higher education. Procedia Comput. Sci., 100: 941-946.

Bobbert, Y. and H. Mulder, 2015. Governance practices and critical success factors suitable for business information security. Int. Conf. Comput. Intell. Commun. Networks Gov.

De Haes, S., T. Huygh and A. Joshi, 2017. Exploring the Contemporary State of Information Technology Governance transparency in Belgian firms. Inform. Syst. Manage., 34: 20-37. DOI: $10.1080 / 10580530.2017 .1254444$

Denolf, M., J.H. Trienekens, P.M.N. Wognum, J.G.A.J.V.D. Vorst and S.W.F.O. Omta, 2015. Computers in industry towards a framework of critical success factors for implementing supply chain information systems. Comput. Ind., 68: 16-26.

El-mekawy, M., L. Rusu and E. Perjons, 2015. An evaluation framework for comparing business-IT alignment models: A tool for supporting collaborative learning in organizations. Comput. Human Beha., 51: 1229-1247. DOI: 10.1016/j.chb.2015.12.016

Hamid, Z.A. and H. Sulaiman, 2016. Cobit benchmarking of system development governance for a government agency in Malaysia. J. Theor. Applied Inform. Techno., 89: 1-6.

Hatsu, S. and E.K. Ngassam, 2015. An exploration of critical success factors for e-Governance project initiation: A preliminary framework. Proceedings of the IST-Africa Conference, May 6-8, IEEE Xplore Press, Lilongwe, Malawi, pp: 1-8. DOI: 10.1109/ISTAFRICA.2015.7190547

Henrique, P.D.S.B., A.O. Tonelli, A.L. Zambalde, P. Aparecida and D. Santos et al., 2014. Evaluating IT Governance practices and business and IT outcomes: A quantitative exploratory study in Brazilian companies. Procedia Technol., 16: 849-857.
İnci, Ş.Ş. and M.D. Griffiths, 2019. Internet gaming disorder and its associated personality traits: A systematic review using PRISMA guidelines. Int. J. Mental Health Addict., 2: 18-29.

Jayant, A. and M. Azhar, 2014. Analysis of the barriers for implementing Green Supply Chain Management (GSCM) practices: An Interpretive Structural Modeling (ISM) approach. Procedia Eng., 97: 2157-2166.

Karadayi, U., 2019. An interpretive structural analysis for industry 4.0 adoption challenges. IEEE Trans. Eng. Manage., 3: 1-6. DOI: 10.1109/TEM.2019.2890443

Kuusk, A. and J. Gao, 2015. Factors for successfully integrating operational and information technologies. Portl. Int. Conf. Manag. Eng. Technol., 5: 1513-1523.

Majid, H.A., M.I. Ibrahim, W.N.S.W. Manan and M.R. Ramli, 2015. Investigation of security awareness on e-learning system among lecturers and students in higher education institution. Proceedings of the International Conference on Computer, Communications and Control Technology, Apr. 21-23, IEEE Xplore Press, Kuching, Malaysia, pp: 216-220. DOI: $10.1109 /$ I4CT.2015.7219569

Paper, C., 2015. Definition of a model for measuring the effectiveness of Information Technology Governance: A study of the moderator effect of organizational culture variables. Definit. Model Measur. Effect. Inform. Technol. Gov.

Pau, F., A. Langeland and B.O. Njå, 2016. Assessing cultural influences in megaproject practices. IEEE Eng. Manage. Rev., 44: 56-73.

Rychkova, I. and J. Zdravkovic, 2017. Information Technology Governance in Public Organizations. 38th Edn., Springer International Publishing, ISBN-10: 978-3-319-58978-7, pp: 286.

Sabry, A., 2014. Factors critical to the success of six-sigma quality program and their influence on performance indicators in some of the Lebanese hospitals. Arab Econ. Bus. J., 9: 93-114.

Safdar, M., G. Richards and B. Raahemi, 2015. A model of effective IT Governance for collaborative networked organizations. Proceedings of the 12th International Joint Conference on e-Business and Telecommunications, Jul. 20-22, IEEE Xplore Press, Colmar, France, pp: 191-202.

Sayogo, D.S. and J.R. Gil-Garcia, 2015. Analyzing the influence of governance structure determinants on the success of inter-organizational information sharing initiatives. Proceedings of the 48th Hawaii International Conference on System Sciences, Jan. 5-8, IEEE Xplore Press, Kauai, HI, USA, pp: 2232-2241. DOI: 10.1109/HICSS.2015.267 
Shelly, T.P.L. J.W. Ping and D.W. Straub, 2015. How Information Technology Governance mechanisms and strategic alignment influence organizational performance: Insights from a matched survey of business and IT managers. Manag. Inform. Syst. Q., 39: 497-518.

Smits, D. and J.V. Hillegersberg, 2018. The continuing mismatch between IT Governance maturity theory and practice: A new approach. Procedia Comput. Sci., 138: 549-560. 10.1016/j.procs.2018.10.075

Teh, D. and B. Corbitt, 2015. Building sustainability strategy in business. J. Bus. Strategy, 36: 39-46.

Tokta, P., E. Baylav, S. Teoman and M. Altunbey, 2014. The impact of barriers and benefits of e-procurement on its adoption decision: An empirical analysis. Int. J. Product. Econ., 158: 77-90.

Yadav, D.K. and A. Barve, 2015. Analysis of critical success factors of the humanitarian supply chain: An application of Interpretive structural modeling. Int. J. Disaster Risk Redu., 12: 213-225.

Yudatama, U. and R. Sarno, 2015. Evaluation maturity index and risk management for IT Governance using fuzzy AHP and fuzzy topsis. Int. Semin. Intell. Technol. Applicat., 5: 323-328.

Yudatama, U. and R. Sarno, 2016. Priority determination for higher education strategic planning using balanced scorecard, FAHP and TOPSIS (Case study: XYZ university). IOP Conf. Ser. Mater. Sci. Eng., 105: 1-8. DOI: $10.1088 / 1757-899 \mathrm{X} / 105 / 1 / 012040$
Yudatama, U., A.N Hidayanto and B. Nazief. 2017a. Awareness and attitudes toward IT Governance: Empirical study. J. Theor. Applied Inform. Technol., 95: 2680-2687.

Yudatama, U., B. Nazief, A.N. Hidayanto and M. Mishbah, 2017b. Factors affecting awareness and attitude of IT Governance implementation in the higher education institution: A literature review. Proceedings of the 3rd International Conference on Science in Information Technology, Oct. 25-26, IEEE Xplore Press, Bandung, Indonesia, pp: 588-592. DOI: 10.1109/ICSITech.2017.8257181

Yudatama, U., A. Setiawan and A. Trismanto, 2017c. Alignment between Val IT and risk IT for choosing a business strategy by fuzzy analytical hierarchy process and TOPSIS. Adv. Sci. Lett., 23: 2492-2494.

Yudatama, U., B. Nazief and A.N. Hidayanto, 2017d. Strategic decisions in the implementation of Information Technology Governance to achieve business and information technology alignment using analytical hierarchy process. Inform. Technol. J., 16: 51-61.

Yudatama, U., A.N Hidayanto and B. Nazief, 2018. Documents and IT resources as essential element in awareness IT Governance: An analysis of study. J. Theor. Applied Inform. Technol., 96: 15-22.

Zou, W., M. Kumaraswamy, J. Chung and J. Wong, 2014. Identifying the critical success factors for relationship management in PPP projects. Int. J. Project Manage., 32: 265-274. DOI: 10.1016/j.ijproman.2013.05.004 